\title{
Objectively measured physical activity according to the periods of the day in the Pelotas Cohort
}

\author{
Medida objetiva de atividade física de acordo com períodos do dia em uma coorte \\ de Pelotas
}

\begin{abstract}
AUTHOR'S
Andrea Wendt ${ }^{1}$ (iD

Fernando C. Wehrmeister ${ }^{1}$

Luiza I. C. Ricardo ${ }^{1}$ (D)

Bruna Gonçalves C. da Silva ${ }^{1}$ (D)

Rafaela C. Martins ${ }^{1}$ (D)

Helen Gonçalves ${ }^{1}$ (D)

Felipe F. Reichert ${ }^{2}$ (D)

Inácio Crochemore-Silva ${ }^{1,2}$

1 Postgraduate Program in Epidemiology, Federal

University of Pelotas, Pelotas, Brazil.

2 Postgraduate Program in Physical Education,

Federal University of Pelotas, Pelotas, Brazil.
\end{abstract}

\section{CORRESPONDING}

\section{Andrea Wendt}

andreatwendt@gmail.com

Marechal Deodoro, 1160 - 3rd Floor,

Pelotas, Rio Grande do Sul, Brazil.

Postal code: 96020-220.

\section{DOI}

10.12820/rbafs. $25 \mathrm{e} 0149$

\section{(cc) BY}

This work is licensed under a Creative Commons Attribution 4.0 International License.

\begin{abstract}
This study aims to describe objectively measured physical activity (PA) in different periods of the day in young adults according to sex, socioeconomic position and during weekdays and weekends. This is a cross-sectional analysis carried out with the participants of the 1993 Pelotas Birth Cohort at 22 years. PA was assessed by triaxial accelerometer. Descriptive analyses were performed presenting the time spent on light PA (LPA) and bouted moderate to vigorous PA (MVPA) in different periods of the day (morning - 6am to 11:59 am, afternoon $-12 \mathrm{pm}$ to 7:59 pm and night $-8 \mathrm{pm}$ to 11:59pm). The present study included 2,766 individuals (48.2\% male and 51.8\% female). LPA was higher among women, while bouted MVPA levels were higher among men. The median of PA was higher on weekdays compared to weekends for all intensities. The bouted MVPA medians in the morning and at night were zero minutes for all days and both sexes. The richest group presented a higher percentage of individuals with zero minutes. PA may vary according to different periods of the day and intensity. The absence of PA practice was markedly influenced by sex and socioeconomic position.
\end{abstract}

Keywords: Motor activity; Physical activity; Accelerometry; Periodicity.

RESUMO

Este estudo teve o objetivo de mensurar atividade física (AF) objetivamente em diferentes periodos do dia em adultos jovens de acordo com sexo, posição socioeconômica e dia de semana e final de semana. Esta é uma análise transversal conduzida com participantes da Coorte de Nascimentos de 1993 de Pelotas aos 22 anos. AF foi avaliada por um acelerômetro triaxial. Foram realizadas análises descritivas apresentando o tempo em $A F$ leve (AFL) e moderada a vigorosa (AFMV) em diferentes periodos do dia (manhã $-6 \mathrm{~h}$ às $11: 59 \mathrm{~h}$, tarde $-12 \mathrm{~h}$ às 19:59h e noite $-20 \mathrm{~b}$ às Ob). O presente estudo incluiu 2.766 individuos (48.2\% homens e $51.8 \%$ mulheres). AFL foi maior entre as mulheres enquanto AFMV foi maior entre os homens. A mediana de AF foi maior nos dias de semana comparado aos dias de final de semana para qualquer intensidade. As medianas de AFMV pela manhã e noite foram zero minutos para todos os dias nos dois sexos. O grupo econômico mais alto apresentou maior percentual de individuos com zero minutos de AFMV. AF pode variar de acordo com diferentes periodos do dia e intensidades. A ausência de prática de AF foi marcadamente influenciada por sexo e posição socioeconômica.

Palavras-chave: Atividade física; Acelerometria; Periodicidade.

\section{Introduction}

Physical activity is considered a complex behaviour since it is influenced by a variety of individual, social, and environmental correlates ${ }^{1}$. Among adults, there is consensus in the literature that males, younger individuals, and wealthier people have a higher probability of physical activity practice during their leisure time $^{2-4}$. The DEDIPAC study focuses on the analysis of physical activity determinants through an umbrella literature review. Their results suggest that sex is one of the most important determinants of physical activity across the lifespan, showing association in more than
$75 \%$ of the published evidence 5 . In addition, socioeconomic status is consistently correlated with physical activity in adults ${ }^{6}$, where total physical activity is higher among poorer groups, mainly practiced during labour and commuting activities ${ }^{2}$.

Furthermore, some issues related to physical activity engagement, such as the period of the day in which individuals are more active, are not well established yet and may vary according to the studied population. Evidence shows that North American older adults are more physically active around 11:00 $\mathrm{am}^{7,8}$, while a study from the United Kingdom comparing obese with non obese adults 
showed greater physical activity levels in the morning for both groups ${ }^{9}$. The literature on this topic lacks populational studies comprising broader age ranges and are concentrated on high income countries. A study showed that physical activity intensity patterns differ according to the day of the week, with increased light intensity activities and decreased moderate-to-vigorous activities at weekends compared to weekdays ${ }^{10}$. Moreover, individuals who practice physical activity at night possibly present a different profile than those who practice physical activity in the morning or afternoon in terms of sex and socioeconomic position ${ }^{11,12}$. One possibility for these differences is that those individuals with higher physical activity practice on night may be involved in specific activities during the day (e.g. no flexible work schedule or very sedentary work during the day ${ }^{11,12}$ ) and the time available to leisure activities is only at night.

There are expected physiological differences due to specificities in terms of correlates and volume/magnitude of physical activity levels according to the period of the day. Cortisol and testosterone are hormones responsible for adaptation and increase in fat-free mass, respectively, and the hormones have different peak variations along the day ${ }^{13}$. Also, vigorous physical activity practice at night may have effects on cardiac autonomic control during the first sleeping hours ${ }^{14}$. In addition, early morning may be the most beneficial time to engage in aerobic exercise to enhance nocturnal blood-pressure changes and quality of sleep ${ }^{15}$. However, a recent meta-analysis has shown that evening physical activity does not affect sleep ${ }^{16}$. Thus, identifying periods with higher physical activity during the day may help further studies to investigate the consequences of the time practice for health outcomes.

In this sense, identifying patterns of physical activity practice in different periods of the day could help to guide effective population-based interventions to promote physical activity attending the participants' needs related to physical activity practice. In the present study, we aimed to describe objectively measured physical activity in different periods of the day (morning, afternoon, and night) in young adults according to sex, socioeconomic position and during weekdays and weekends. We also presented the description of the absence of bouted MVPA and its distribution according to sex and wealth quintiles.

\section{Methods}

This study was carried out with the participants of the
1993 Pelotas Birth Cohort at 22 years (a cross-sectional analysis). In 1993, all maternity hospitals in Pelotas (Brazil) were visited from January $1^{\text {st }}$ to December $31^{\text {st }}$, and all live births were identified. All hospital-born children with mothers living in the urban areas of the city were eligible to participate in the 1993 Pelotas Birth Cohort Study. Out of 5,265 eligible live births, 5,249 mothers (99.7\%) agreed to participate. Participants have been followed-up several times throughout childhood and adolescence. The Ethics Committee of the Medical School of the Federal University of Pelotas approved all data collections of the 1993 Pelotas Birth Cohort Study, and all participants signed an informed consent form or consented to participate verbally at each visit. Further details on the study design and methods can be found elsewhere ${ }^{17-19}$.

The 22-year-old follow-up assessment occurred from October 2015 to July 2016. All located participants were invited to attend the cohort clinic for interviews and physical examinations. A total of 3,810 participants completed the interviews at this follow up. The follow-up rate was 76.3\% (accounting those who had died, $N=193$ ). At the end of the visit, participants were invited to wear a triaxial accelerometer (ActiGraph ${ }^{\circledR}$ wGT3X+) on their non-dominant wrist for six days with a 24 -hour protocol ${ }^{17}{ }^{18}$. Participants were asked to remove the device only at the end of the period (not removing during sleep and water activities). The choice for wrist-worn accelerometer was made based on a better compliance in free-living population-based studies with large sample sizes. Data were collected with five seconds epoch and $60 \mathrm{~Hz}$ sampling frequency, downloaded in Actilife 6.1 software and processed in R-package GGIR version 1.5-21 (http:// cran.r-project.org) ${ }^{20}$. This process makes a post-calibration process using local gravity as a reference ${ }^{21}$, non-wear time, and abnormally high values detection and calculates vector magnitude using Euclidian Norm minus $1 g\left(\mathrm{ENMO}=\sqrt{\mathrm{x}^{2}+\mathrm{y}^{2}+\mathrm{z}^{2}}-1 g\right)$. Regarding the raw data analysis in GGIR, the choice was made taking into account the use of an open source tool that provides the researcher control of the analysis in each step of process and is free of commercial issues, making the analysis process replicable with great precision ${ }^{20}$.

We analyzed the time spent on light physical activity (LPA) and bouted moderate to vigorous physical activity (MVPA) in different periods of the day during weekdays and weekends. LPA was defined based on acceleration from $50 \mathrm{mg}$ to $99 \mathrm{mg}$, while bout- 
ed MVPA was defined as acceleration $\geq 100 \mathrm{mg}$. The proposed thresholds have been previously used, and they are based on results of activity-specific intensities recommended in a calibration study ${ }^{22}$. We opted to use non-bouted LPA due to the intermittent nature of such intensity, therefore capturing more general activities in a day. Bouted MVPA is presented using 5-minute bouts, as we have attempted to extract more structured activities from the analyses.

Periods of the day were divided in morning, afternoon, and night. The morning was considered the period from 6 am to 11:59 am, afternoon from $12 \mathrm{pm}$ to $7: 59 \mathrm{pm}$, and night from $8 \mathrm{pm}$ to $11: 59 \mathrm{pm}$. The periods were defined based on the structure of activities in Brazil with the end of the morning marked by lunch (usually at noon) and the end of the afternoon marked by office hour. We extended afternoon period until 8pm taking in account that many individuals practice physical activity after work and before returning home. Furthermore, because of daylight saving time, the sun light was present until $8 \mathrm{pm}$ during part of the data collection. We analyzed data from 6 am to $11: 59 \mathrm{pm}$ to exclude periods of sleep. We included in this analysis individuals with at least 16 hours of data in a day (default in GGIR ${ }^{20}$ ) and with at least three days of use ${ }^{23}$. Furthermore, the 1993 Birth Cohort have some exclusion criteria for accelerometry data collection: pregnant women, work that does not allow the use of wrist-worn devices and residence in a small city near to Pelotas (In the beginning of cohort, this small city was included in the 1993 Birth Cohort and all participants are currently followed-up). From the 3,810 participants with complete interviews, 212 were excluded from our analysis due to accelerometry exclusion criteria, 590 due to losses, refusals or not complying with the protocol (less than three days of accelerometer data), resulting in 3,008 accelerometer data. After data filtering and processing, exclusions due to calibration error, and data quality checks, the final sample comprised 2,766 individuals.

Our descriptive analyses presented means and medians of LPA and bouted MVPA according to sex, periods of the day, and days of the week. To compare medians in weekdays and weekends we used the Wilcoxon matched-pairs signed-rank test and carried out a Bonferroni adjustment for multiple comparisons. Results were presented considering the non-adjusted significance level of 5\% and the significance level obtained with the Bonferroni adjustment. In addition, due to the relatively high levels of participants with zero minutes of bouted MVPA in different periods of the day, we also described such frequencies in the mornings, afternoons, and at nights on weekdays and weekends and according to sex and wealth quintiles using 95\% confidence intervals to enable the comparison between these percentages. We also tested the linear trend to verify the behaviour of zero minutes of MPA variables according to wealth quintiles. The wealth index was obtained from an asset list, and, after that, a principal component analysis was calculated and the first component was divided in quintiles, where first indicates the poorest and the fifth the richest population ${ }^{24}$. This procedure allowed the attainment of a sample-specific wealth index which is more appropriate to the study population. For all frequencies, we presented a 95\% confidence interval (95\% CI). All statistical analyses were performed using Stata version 15.0 (StataCorp, College Station, TX, USA).

\section{Results}

The present study included 2,766 individuals. No difference was found between individuals included in the 22-year-old follow-up $(n=3,810)$ and the analyzed sample $(n=2,766)$ regarding sex $(p=0.276)$, skin colour $(p=0.245)$, and wealth quintiles $(p=0.940)$. The sample is comprised of $51.8 \%$ females and $61.8 \%$ white individuals. A brief description of the sample according to sociodemographic variables is presented in supplementary Table 1 . The median of physical activity was frequently higher on weekdays compared to weekends (Figure 1 and Supplementary Table 2). The differences between weekdays and weekends were more pronounced when assessing bouted MVPA.

Table 1 - Prevalence of individuals with zero minutes of bouted MVPA in the morning, afternoon and night on weekdays and weekends for men and women.

\begin{tabular}{lcccc}
\hline & \multicolumn{2}{c}{ Men } & \multicolumn{2}{c}{ Women } \\
\cline { 2 - 5 } & Weekdays & Weekend days & Weekdays & Weekend days \\
$\%(95 \% \mathrm{CI})$ & \% (95\% CI) & $34.5(32.1 ; 37.0)$ & $60.6(58.0 ; 63.3)$ \\
\hline Morning & $29.3(26.8 ; 31.7)$ & $56.2(53.4 ; 59.0)$ & $11.0(9.3 ; 12.6)$ & $31.9(29.4 ; 34.4)$ \\
Afternoon & $8.1(6.6 ; 9.6)$ & $26.8(24.3 ; 29.3)$ & $51.0(48.3 ; 53.6)$ & $67.4(64.9 ; 70.0)$ \\
Night & $36.7(34.1 ; 39.3)$ & $55.1(52.2 ; 58.9)$ & \\
\hline
\end{tabular}


Figure 2 shows the medians of LPA and bouted MVPA according to sex for each day and period of the day. LPA was stable during the week, presenting a decrease only on Sundays. The bouted MVPA medians in the morning and at night were zero minutes for all days and both sexes. In the afternoon, the bouted MVPA median was 6.5 minutes higher on weekdays compared to weekend days for men (15.5 on weekdays vs. 9.0 on weekend days, $p<0001)$. For women, this difference was about 5 minutes (10.1 on weekdays vs.
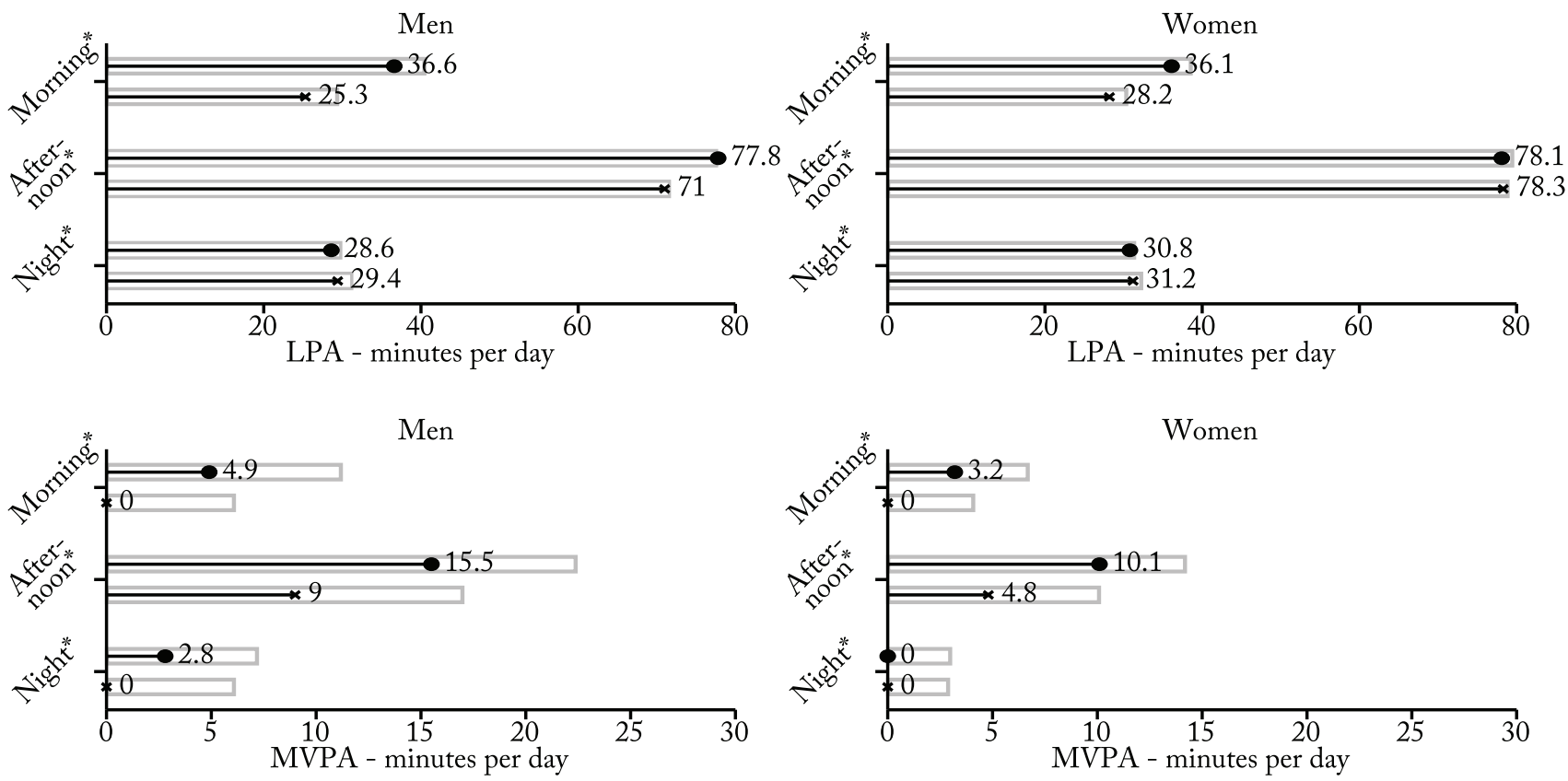

Median in Weekdays

Median in Weekend days

Mean

Figure 1 - Medians of light and moderate to vigorous physical activity on weekdays and weekend according to sex and period of day. * P-value < 0,004 (Wilcoxon matched-pairs signed-rank test with adjustment to multiple comparisons)
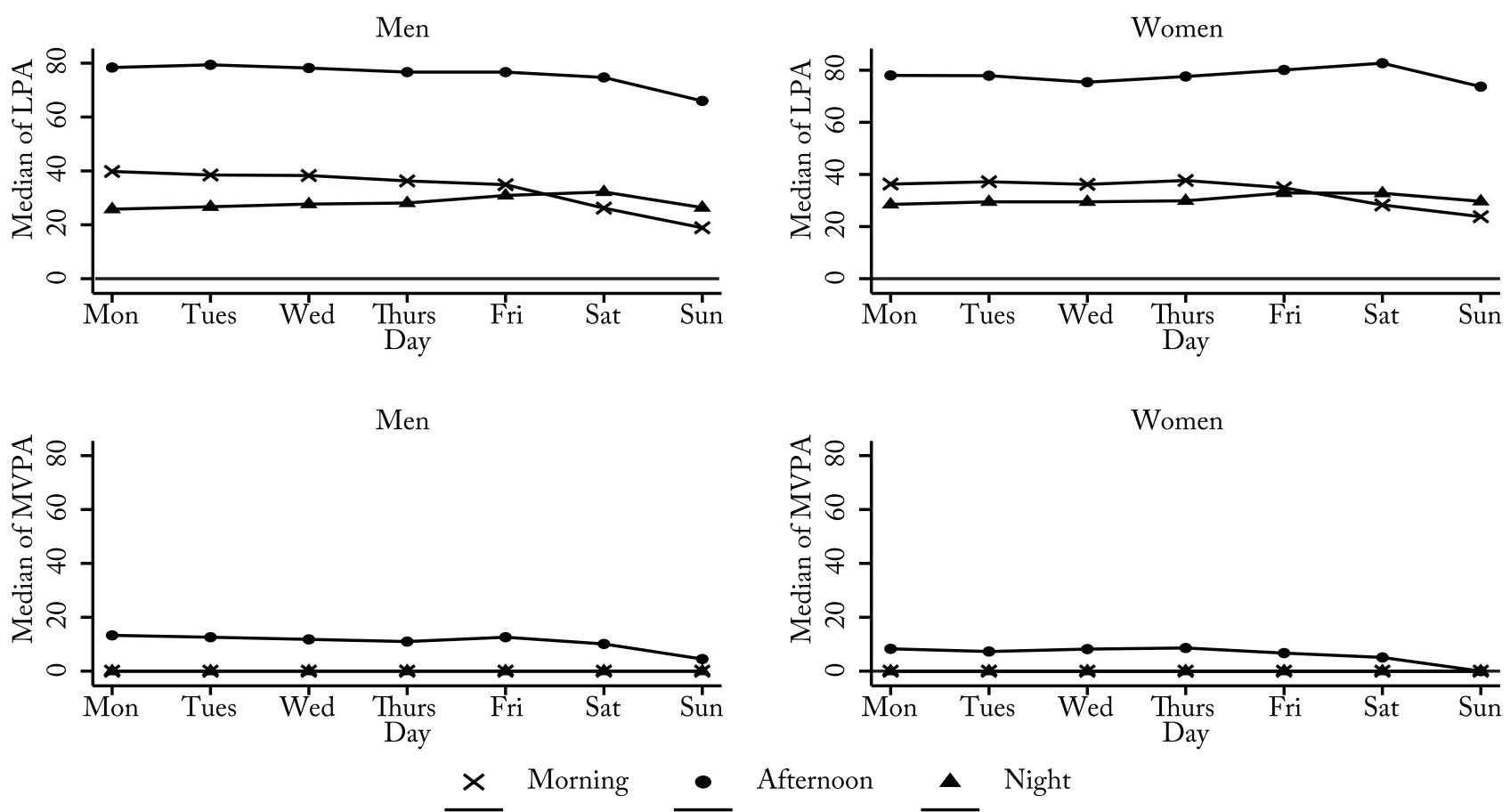

Figure 2 - Median of light and moderate to vigorous physical activity according to each day of the week, period of day and sex. 


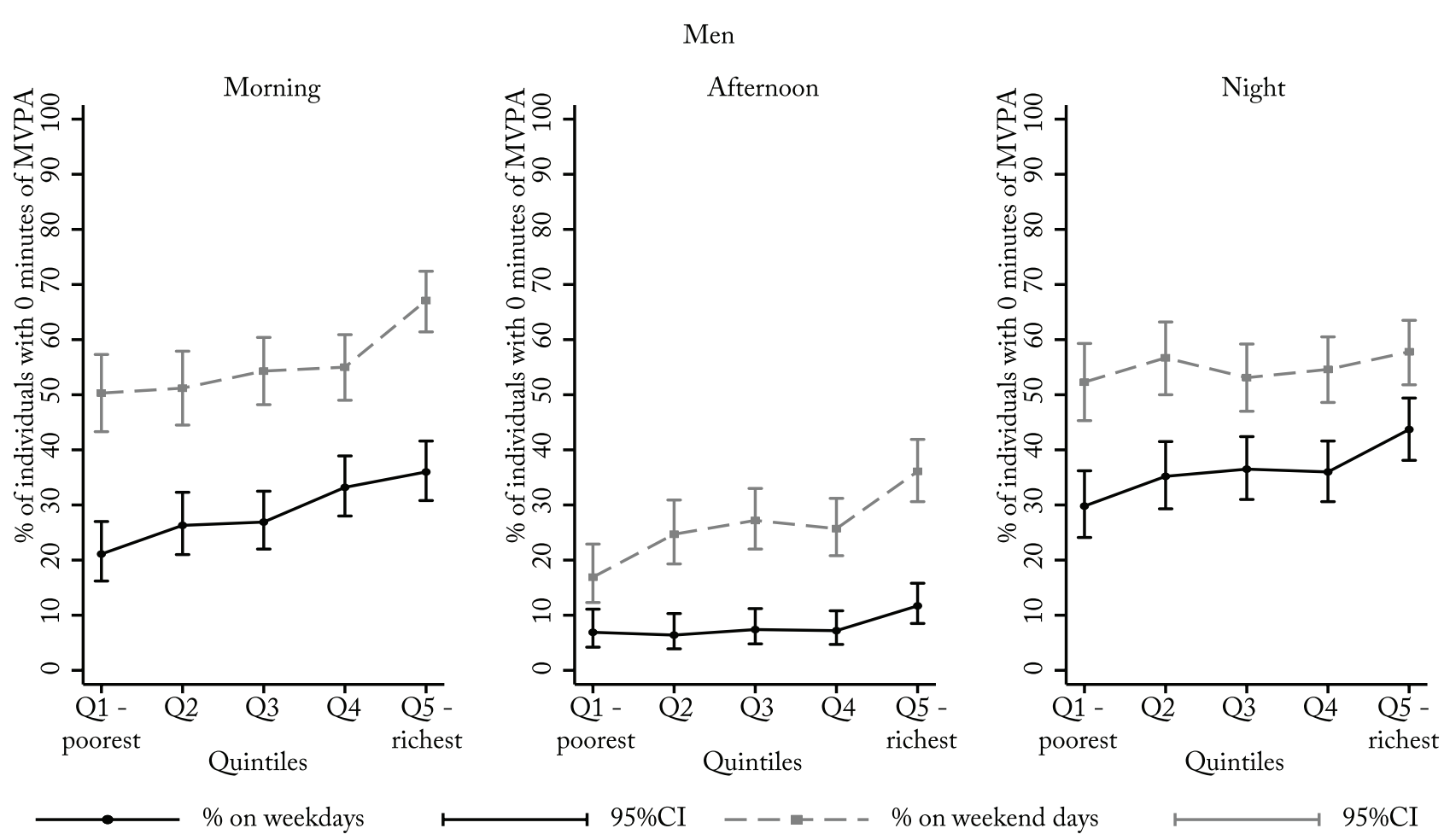

Figure 3 - Percent of individuals with zero minutes of bouted MVPA in the morning, afternoon and at night according to wealth quintiles among men.

All variables except morning bouted MVPA at weekdays presented linear trend $(\mathrm{p}<0.05)$.

Women
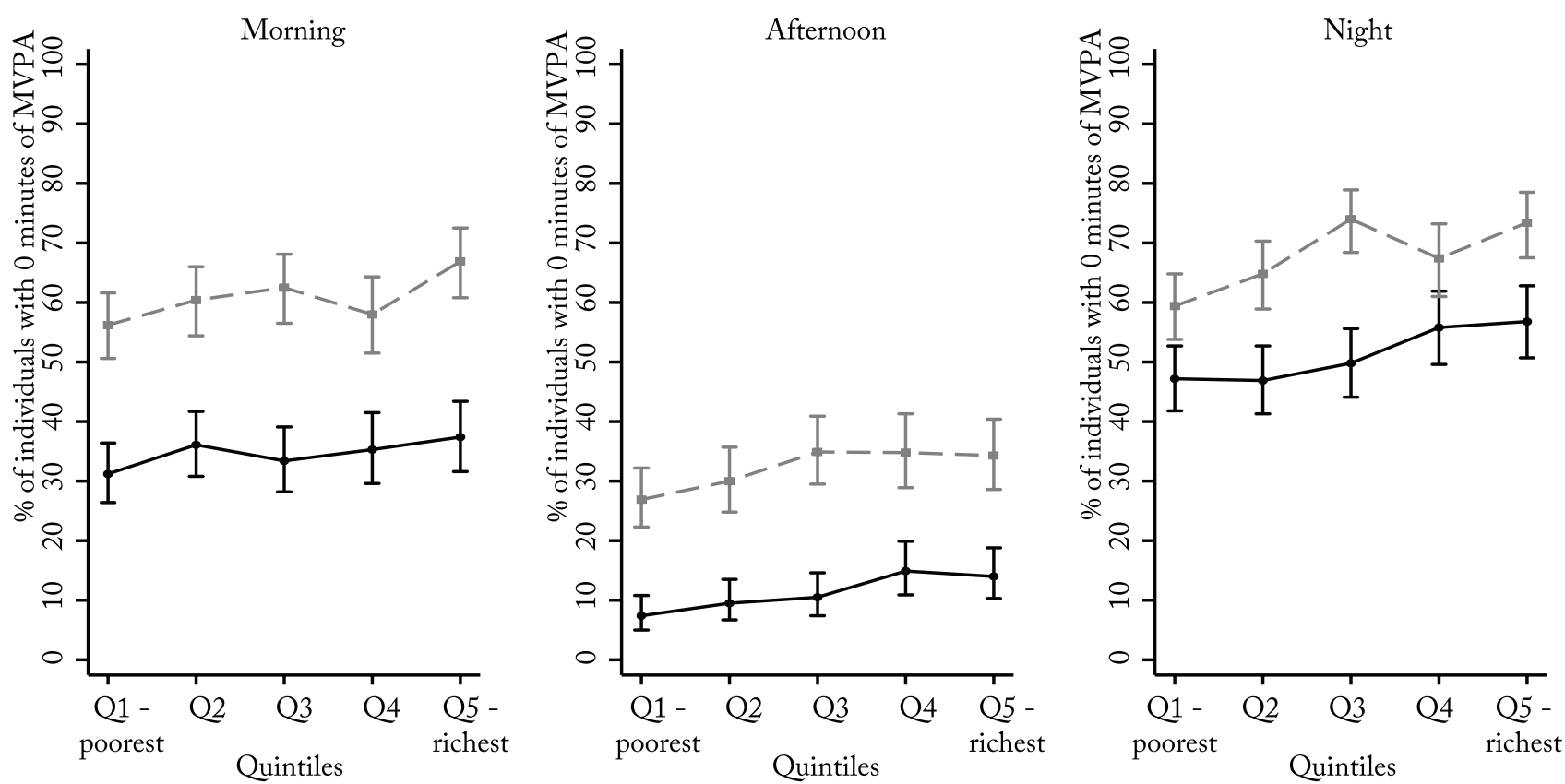

$\%$ on weekdays

95\%CI

$\%$ on weekend days

$95 \% \mathrm{CI}$

Figure 4- Percent of individuals with zero minutes of bouted MVPA in the morning, afternoon and at night according to wealth quintiles among women.

All variables except night bouted MVPA at weekend days presented linear trend $(\mathrm{p}<0.05)$. 
4.8 on weekends days, $\mathrm{p}<0001$ ).

Table 1 describes the absence of physical activity by presenting the percentage of individuals with zero minutes in bouted MVPA according to sex and period of the day for weekdays and weekends. In the morning, almost $30 \%$ of men presented zero minutes of bouted MVPA on weekdays, and during the weekends this proportion was even higher in this gender group (56.2\%). Among women, these percentages were $34.5 \%$ and $60.6 \%$ during weekdays and weekends, respectively. In the afternoon, the absence of bouted MVPA practice was less frequent, and the percentage of individuals with zero minutes on weekdays was $8.1 \%$ for men and $11.0 \%$ for women. However, at weekends, these percentages were more than twice higher $(26.8 \%$ for men and $31.9 \%$ for women). At night, the percentage of men with zero minutes of bouted MVPA is similar to the morning periods. However, for women, these values reached $51 \%$ on weekdays and $67.4 \%$ at weekends.

Among men, for all periods of the day, the richest group presented a higher percentage of individuals with zero minutes. The difference between weekdays and weekends was always significant and more pronounced during the morning period (Figure 3 and Supplementary Table 3). For all physical activity variables, except morning bouted MVPA at weekdays, a linear trend was found between percentage of individuals with zero minutes and wealth quintiles $(\mathrm{p}<0.05)$. Among women (Figure 4), despite higher percentages of zero minutes of bouted MVPA, a similar pattern was observed in terms of wealth. For all variables in Figure 4, except night bouted MVPA at weekends, a linear trend was found between percentage of individuals with zero minutes and wealth quintiles $(p<0.05)$.

\section{Discussion}

The present study focused on an innovative descriptive approach of objectively-measured physical activity according not only to different levels of practice on weekdays and weekends but also to the periods of the day with higher and lower practice. The afternoon was identified as the period of the day with higher activity levels. Medians on weekdays were always higher than weekends, and the day of the week with the least activity was Sunday.

Differences in physical activity levels between periods of the day might represent essential advances in terms of a descriptive approach and may help design future interventions. In this sense, some previous stud- ies found evidence that supports our results. Varma et al. ${ }^{25}$ carried out a study in the United States including different age groups, which presented higher activity levels between noon and 8pm. Similarly, a British study with older adults showed that the peak for time spent in sedentary activity was between 8 pm and 9 $\mathrm{pm}^{26}$. The pattern for weekdays and weekend days was the similar to the observed in our study, however, on weekends, sedentary time was considerably higher ${ }^{26}$. In the same direction, Cerin et al. ${ }^{27}$, evaluating physical activity using accelerometry in 10 different countries, found lower medians of bouted MVPA in the morning and evening compared with the afternoon period. The authors also suggest that environmental characteristics (e.g. walkability) may play a relevant role in the periods 'before- and after-work' and design intervention aiming at impacting such characteristics may be an interesting strategy to increase the activity levels at these specific time periods ${ }^{27}$.

Analyses in the present study also explore the difference between weekday and weekend physical activity levels. The medians for LPA and bouted MVPA were lower on weekends, and the percentage of individuals with zero minutes for bouted MVPA was higher, indicating a lower level of activity on weekends, corroborating with other studies carried out with younger groups $^{26,28}$. For LPA, the medians on weekdays and weekend days were similar in the afternoon and at night, however, LPA in the morning was lower on weekends. Also, lower levels of bouted MVPA were found on weekends, for all periods of day. Analyzing day-by-day medians, we may conclude that Sundays are responsible for the lower means at weekends. In Brazil, Saturdays are regular workdays for many occupational activities, and this may justify the reason why only on Sundays we have lower activity levels. In our sample, more than $60 \%$ of individuals reported having a job (data not shown), reinforcing that occupational physical activity may have played an important role in the bouted MVPA median. However, we believe that even those who do not have a periodic work rhythm, such as unemployed individuals, tend to adopt patterns of daily activities to match their activities to the schedule of their peers and the business hours of local facilities ${ }^{29}$. Also, during the weekend, people have more freedom to make their behavioral choices and may be more likely to engage in sedentary activities in order to compensate for weekdays activities.

Regarding the different constructs of physical activity, we used non-bouted LPA and bouted MVPA with 
5-minute bouts. We believe that this definition may capture two different constructs: LPA representing daily activities and bouted MVPA for structured exercises or continued periods of labor-related physical activity. It is well established in the literature that the bout duration/existence strongly impacts the physical activity estimates ${ }^{30}$. Orme et al. ${ }^{30}$ showed that the mean of time spent in a one-minute bout of MVPA was almost 20 minutes. However, the mean was lower than $10 \mathrm{~min}-$ utes when using a five-minute bout of MVPA. We performed a sensitivity analysis with non-bouted MVPA and found a similar pattern to the five-minute-bouted MVPA results, even though the magnitude of means and medians were higher for non-bouted measures.

Regarding the sex of the sample, the main difference between men and women was in terms of MVPA. Men traditionally spend more time in physical activity than women ${ }^{1,31}$. In our study, we identified that men presented a higher bouted MVPA median compared to women; for LPA, the median between sexes was similar (women showed slightly higher magnitude). A previous study using accelerometry showed that women spent more minutes across the day in LPA, but for bouted MVPA, the medians were higher in men $^{32}$. These differences may occur due to movement patterns, as men are more engaged in structured activities with higher intensities while women spend more time in non-structured low intensity activities.

Regarding the differences observed according to wealth groups, we have found that, in all periods of the day, individuals in the richest group always presented a higher percentage of zero minutes of bouted MVPA than those in the poorest group. Data from accelerometers do not provide information on the domains of physical activity; however, we could speculate that our results are expressing mostly occupational and commuting physical activity. Vandelanotte et al. ${ }^{12}$, in a study by telephone interviews with a sample of workers from Australia, showed that occupational physical activity presented a more significant impact on the total amount of physical activity than leisure-time. Probably, individuals in the richest groups are more engaged in sedentary work activities (e.g., white-collar jobs) or studying. In contrast, individuals in the poorest groups are more engaged in work activities requiring physical effort (e.g., blue-collar jobs) ${ }^{12}$. Also, individuals with higher socioeconomic status commonly commute by car, and those with lower socioeconomic status present higher active commuting ${ }^{12}$. A previous study with data from three Brazilian birth cohorts (including data at 18 years of the 1993 Pelotas birth Cohort) showed an inverse association between physical activity assessed by accelerometer and socioeconomic status, corroborating with our hypothesis ${ }^{31}$.

Our results must be interpreted in light of some limitations. Firstly, the thresholds for wrist accelerometry raw data are still fragile, and more calibration studies with different populations are needed. On the other hand, this does not have an impact on the direction of results. Secondly, data on objectively-measured physical activity used in this work includes only one week of data. Longer periods of accelerometer usage may decrease the effect of the extreme values found in some days, which may affect the final physical activity means for weekdays and weekend days. Lastly, the follow-up assessment did not include the months of August and September and may not reflect all seasonality in physical activity. However, we believe this fact is minimized as we did not include only two months of the year. Nevertheless, the present analysis has strengths, such as the fact that it is a population-based sample of young adults. Besides, data from raw accelerometry obtained from an open-source tool may contribute to transparency in science ${ }^{20}$. Another strength is that few studies describe physical activity according to periods of the day in free-living situations for lowand middle-income countries. Thus, this study may fill a gap in the literature, helping to plan strategies aiming at the promotion of physical activity.

Summing up, levels of physical activity may vary according to different periods of the day, intensity and weekdays, and weekends. Furthermore, the absence of physical activity practice was markedly influenced by sex and socioeconomic position. More studies investigating objective measures associated with self-report information of physical activity domains may help to understand such behavior and provide directions for future physical activity interventions.

\section{Conflict of interest}

The authors declare no conflict of interest.

\section{Author's contributions}

Wendt A and Crochemore-Silva I conceptualized the paper. Wendt A, Ricardo LIC, Silva BG and Martins RC wrote the first draft and reviewed subsequent drafts. Crochemore-Silva I, Wehrmeister FC, Gonçalves $\mathrm{H}$ and Reichert FF reviewed and carried out a critical analysis. All authors approved the final manuscript. 


\section{Acknowledgments}

The authors thank the members of the Research Group GEPEA (Grupo de Estudos e Pesquisas em Acelerometria). This study was financed in part by the Coordenação de Aperfeiçoamento de Pessoal de Nível Superior - Brasil (CAPES) (Finance Code 001) and the Science and Technology Department/ Brazilian Ministry of Health, with resources transferred trough the Brazilian National Council for Scientific and technological (CNPq) (400943/2013-1).

\section{References}

1. Bauman AE, Reis RS, Sallis JF, Wells JC, Loos RJF, Martin BW, et al. Correlates of physical activity: why are some people physically active and others not? Lancet (London, England). 2012;380(9838):258-71.

2. Silva ICM, Mielke GI, Bertoldi AD, Arrais PSD, Luiza VL, Mengue SS, et al. Overall and Leisure-Time Physical Activity Among Brazilian Adults: National Survey Based on the Global Physical Activity Questionnaire.J Phys Activ Health. 2018;15(3):212-18.

3. Crochemore-Silva I, Knuth AG, Mielke GI, Loch MR. Promoção de atividade física e as políticas públicas no combate às desigualdades: reflexões a partir da Lei dos Cuidados Inversos e Hipótese da Equidade Inversa. Cad Saúde Pública. 2020;36(6):e00155119.

4. Ide PH, Martins MSAS, Segri NJ. Tendência dos diferentes domínios da atividade física em adultos brasileiros: dados do Vigitel de 2006-2016. Cad Saúde Pública. 2020;36(8):e00142919.

5. Aleksovska K, Puggina A, Giraldi L, Buck C, Burns C, Cardon G, et al. Biological determinants of physical activity across the life course: a "Determinants of Diet and Physical Activity" (DEDIPAC) umbrella systematic literature review. Sports Med - open. 2019;5(1):2.

6. O’Donoghue G, Kennedy A, Puggina A, Aleksovska K, Buck $\mathrm{C}$, Burns $\mathrm{C}$, et al. Socio-economic determinants of physical activity across the life course: A "DEterminants of DIet and Physical ACtivity" (DEDIPAC) umbrella literature review. PloS one. 2018;13(1):e0190737.

7. Jansen FM, van Kollenburg GH, Kamphuis CBM, Pierik FH, Ettema DF. Hour-by-hour physical activity patterns of adults aged 45-65 years: a cross-sectional study. J public health (Oxford, England). 2018;40(4):787-96.

8. Steeves JA, Shiroma EJ, Conger SA, Domelen DV, Harris TB.. Physical activity patterns and multimorbidity burden of older adults with different levels of functional status: NHANES 2003-2006. Disabil Health J. 2019;12(3):495-502.

9. Cooper AR, Page A, Fox KR, et al. Physical activity patterns in normal, overweight and obese individuals using minute-byminute accelerometry. Eur J Clin Nutr. 2000;54(12):887-94.

10. Gil-Rey E, Maldonado-Martin S, Palacios-Samper N, Gorostiaga EM. Objectively measured absolute and relative physical activity intensity levels in postmenopausal women. Eur J Sport Sci. 2019;19(4):539-48.

11. Kecklund G, Axelsson J. Health consequences of shift work and insufficient sleep. BMJ (Clinical research ed). 2016;355:i5210.

12. Vandelanotte C, Short C, Rockloff M, Di Millia L, Ronan K, Happell B, et al. How do different occupational factors influence total, occupational, and leisure-time physical activity? J Phys Activ Health. 2015;12(2):200-7.
13. Seo DY, Lee S, kim N, Ko KS, Rhee BD, Prak BJ, et al.Morning and evening exercise. Integr Med Res. 2013(2):139-44.

14. Myllymäki T, Kyröläinen H, Savolainen K, Hokka L, Jakonen $\mathrm{R}$, Juuti $\mathrm{T}$, et al. Effects of vigorous late-night exercise on sleep quality and cardiac autonomic activity. J Sleep Res. 2011;20(1 Pt 2):146-53.

15. Fairbrother K, Cartner B, Alley JR, Curry CD, Dickinson DL, Morris DM, et al. Effects of exercise timing on sleep architecture and nocturnal blood pressure in prehypertensives. Vasc Health Risk Manag. 2014;10:691-8.

16. Stutz J, Eiholzer R, Spengler CM. Effects of Evening Exercise on Sleep in Healthy Participants: A Systematic Review and Meta-Analysis. Sports Med (Auckland, NZ). 2019;49(2):269-87.

17. Goncalves H, Assuncao MC, Wehrmeister FC, Oliveira IO, Barros FC, Victoria CG, et al. Cohort profile update: The 1993 Pelotas (Brazil) birth cohort follow-up visits in adolescence. Int J Epidemiol. 2014;43(4):1082-8.

18. Goncalves H, Wehrmeister FC, Assuncao MCF, TovoRodrigues L, Oliveira IO, Murray J, et al. Cohort Profile Update: The 1993 Pelotas (Brazil) Birth Cohort follow-up at 22 years. Int J Epidemiol. 2018;47(5):1389-90e.

19. Victora CG, Hallal PC, Araujo CL, Menezes AMB, Wells JCK, Barros FC. Cohort profile: the 1993 Pelotas (Brazil) birth cohort study. Int J Epidemiol. 2008;37(4):704-9.

20. Migueles JH, Rowlands AV, Huber F, Sabia S, van Hess VT. GGIR: A Research Community-Driven Open Source R Package for Generating Physical Activity and Sleep Outcomes From Multi-Day Raw Accelerometer Data. J Meas Phys Behav. 2019(2):188-96.

21. van Hees VT, Fang Z, Langford J, Assah F, Mohammad A, Silva ICM, et al. Autocalibration of accelerometer data for free-living physical activity assessment using local gravity and temperature: an evaluation on four continents.J Appl Physiol (Bethesda, Md : 1985). 2014;117(7):738-44.

22. Hildebrand M, VT VAN Hees, Hansen BH, Ekelundet U. Age group comparability of raw accelerometer output from wrist- and hip-worn monitors. Med Sci Sports Exer. 2014;46(9):1816-24.

23. Ricardo LIC, Wendt A, Galliano LM, Muller WA, Crux GIN, Wehrmeister F, et al. Number of days required to estimate physical activity constructs objectively measured in different age groups: Findings from three Brazilian (Pelotas) population-based birth cohorts. PloS one. 2020;15(1):e0216017.

24. Rutstein SO, Johnson K. The DHS wealth index. DHS Comparative Reports No 6. Calverton, Maryland, USA: ORC Macro, 2004.

25. Varma VR, Dey D, Leroux A, Di J, Urbanek J, Xiao L, et al. Re-evaluating the effect of age on physical activity over the lifespan. Prev Med. 2017;101:102-08.

26. Konharn K, Santos MP, Ribeiro JC. Differences between weekday and weekend levels of moderate-to-vigorous physical activity in Thai adolescents. Asia Pac J Public Health. 2015;27(2):Np2157-66.

27. Cerin E, Mitas J, Cain KL, Conway TL, Adams MA, Schofield G, et al. Do associations between objectivelyassessed physical activity and neighbourhood environment attributes vary by time of the day and day of the week? IPEN adult study. Int J Behav Nutr Phys Act. 2017;14(1):34. 
28. Ramirez-Rico E, Hilland TA, Foweather L, FernándezGarcia E, Fairclough SJ. Weekday and weekend patterns of physical activity and sedentary time among Liverpool and Madrid youth. Int J Behav Nutr Phys Act. 2014;14(3):287-93.

29. Rowlands AV, Gomersall SR, Tudor-Locke C, Bassett DR, Kang M, Fraysse F, et al. Introducing novel approaches for examining the variability of individuals' physical activity. J Sports Sci. 2015;33(5):457-66.

30. Orme M, Wijndaele K, Sharp SJ, Westgate K, Ekelund U, Brage S. Combined influence of epoch length, cut-point and bout duration on accelerometry-derived physical activity. . Int J Behav Nutr Phys Act. 2014;11(1):34.
31. Silva IC, van Hees VT, Ramires VV, Knuth AG, Bielemann $\mathrm{RM}$, Ekelund U, et al. Physical activity levels in three Brazilian birth cohorts as assessed with raw triaxial wrist accelerometry. Int J Epidemiol 2014;43(6):1959-68.

32. Amagasa S, Fukushima N, Kikuchi H, Takamiya T, Oka K, Inoue S. Light and sporadic physical activity overlooked by current guidelines makes older women more active than older men. Int J Behav Nutr Phys Act. 2017;14(1):59.

Received: $17 / 07 / 2020$

Approved: $26 / 10 / 2020$

\section{Quote this article as:}

Wendt A, Wehrmeister FC, Ricardo LIC, Silva BGC, Martins RC, Gonçalves H, Reichert FF, Crochemore-Silva I. Objectively measured physical activity according to the periods of the day in the Pelotas Cohort. Rev Bras Ativ Fis Saúde. 2020;25:e149. DOI: 10.12820/rbafs. 25 e0149 


\section{Supplementary material}

Supplementary Table 1 - Description of sample.

\begin{tabular}{lccc}
\hline & $\mathrm{n}$ & $\%$ & $95 \%$ CI \\
\hline Sex & & & $46.3 ; 50.0$ \\
Male & 1,332 & 48.2 & $50.0 ; 53.7$ \\
$\quad$ Female & 1,434 & 51.8 & $59.9 ; 63.6$ \\
Skin colour & & & $15.4 ; 18.3$ \\
White & 1,637 & 61.8 & $15.9 ; 18.8$ \\
Black & 446 & 16.8 & $3.4 ; 4.9$ \\
Brown & 458 & 17.3 & \\
Yellow/American Native & 109 & 4.1 & $18.5 ; 21.5$ \\
Wealth quintiles & & & $17.8 ; 20.8$ \\
Q1 - poorest & 551 & 20.0 & $19.0 ; 22.0$ \\
Q2 & 532 & 19.3 & $18.4 ; 21.4$ \\
Q3 & 564 & 20.4 & $19.0 ; 22.0$ \\
Q4 & 549 & 19.9 & 20.5 \\
Q5 - richest & 566 & \\
\hline
\end{tabular}

Supplementary Table 2 - Medians and interquartile interval for sex and period of day in weekdays and weekend days

\begin{tabular}{|c|c|c|c|c|c|c|}
\hline & \multicolumn{3}{|c|}{ Men } & \multicolumn{3}{|c|}{ Women } \\
\hline & Weekdays & Weekend days & $\mathrm{P}$-value & Weekdays & Weekend days & $\mathrm{P}$-value \\
\hline \multicolumn{7}{|l|}{ LPA } \\
\hline Morning & $35.6(18.8 ; 60.7)$ & $25.3(11.3 ; 42.7)$ & $<0.001$ & $36.1(22.5 ; 51.0)$ & $28.2(14.0 ; 42.8)$ & $<0.001$ \\
\hline Afternoon & $77.8(57.8 ; 95.5)$ & $71.0(52.1 ; 89.6)$ & $<0.001$ & $78.1(63.0 ; 95.1)$ & $78.3(59.5 ; 96.9)$ & 0.592 \\
\hline Night & $28.6(21.1 ; 37.3)$ & $29.4(20.7 ; 40.0)$ & 0.001 & $30.8(22.6 ; 38.9)$ & $31.2(22.2 ; 40.8)$ & 0.014 \\
\hline \multicolumn{7}{|l|}{ MVPA } \\
\hline Morning & $4.9(0.0 ; 14.0)$ & $0.0(0.0 ; 7.2)$ & $<0.001$ & $3.2(0.0 ; 9.5)$ & $0.0(0.0 ; 4.8)$ & $<0.001$ \\
\hline Afternoon & $15.5(6.0 ; 29.4)$ & $9.0(0.0 ; 24.1)$ & $<0.001$ & $10.1(4.0 ; 20.4)$ & $4.8(0.0 ; 14.0)$ & $<0.001$ \\
\hline Night & $2.8(0.0 ; 9.8)$ & $0.0(0.0 ; 7.2)$ & $<0.001$ & $0.0(0.0 ; 3.8)$ & $0.0(0.0 ; 3.2)$ & $<0.001$ \\
\hline
\end{tabular}

$\mathrm{p}$-value $=$ Wilcoxon matched-pairs signed-rank test was used for comparisons. Bonferroni adjustment to multiple comparisons identified a significance level $<0,004$.

Supplementary Table 3 - Percent of individuals with zero minutes of bouted MVPA in the morning, afternoon and at night according to wealth quintiles.

\begin{tabular}{|c|c|c|c|c|}
\hline & \multicolumn{2}{|c|}{ Men } & \multicolumn{2}{|c|}{ Women } \\
\hline & Weekdays & Weekend days & Weekdays & Weekend days \\
\hline \multicolumn{5}{|l|}{ Morning } \\
\hline Q1 - poorest & $21.1(16.2 ; 27,0)$ & $50.3(46.3 ; 57.3)$ & $31.2(26.4 ; 36.4)$ & $56.2(50.6 ; 61.6)$ \\
\hline Q2 & $26.3(21.0 ; 32.3)$ & $51.2(44.5 ; 57.9)$ & $36.1(30.8 ; 41.7)$ & $60.4(54.4 ; 66.0)$ \\
\hline Q3 & $26.9(22.0 ; 32.5)$ & $54.3(48.2 ; 60.4)$ & $33.4(28.2 ; 39.1)$ & $62.5(56.5 ; 68.1)$ \\
\hline Q4 & $33.2(28.0 ; 38.9)$ & $55.0(49.0 ; 60.9)$ & $35.3(29.6 ; 41.5)$ & $58.0(51.5 ; 64.3)$ \\
\hline Q5 - richest & $36.0(30.8 ; 41.6)$ & $67.1(61.4 ; 72.4)$ & $37.4(31.6 ; 43.4)$ & $66.9(60.8 ; 72.5)$ \\
\hline \multicolumn{5}{|l|}{ Afternoon } \\
\hline Q1 - poorest & $6.9(4.2 ; 11.1)$ & $16.9(12.3 ; 22.9)$ & $7.4(5.0 ; 10.8)$ & $26.9(22.3 ; 32.2)$ \\
\hline $\mathrm{Q} 2$ & $6.4(3.9 ; 10.3)$ & $24.7(19.3 ; 30.9)$ & $9.5(6.7 ; 13.5)$ & $30.0(24.8 ; 35.7)$ \\
\hline Q3 & $7.4(4.8 ; 11.2)$ & $27.2(22.0 ; 33.0)$ & $10.5(7.4 ; 14.6)$ & $34.9(29.5 ; 40.9)$ \\
\hline Q4 & $7.2(4.7 ; 10.8)$ & $25.7(20.8 ; 31.2)$ & $14.9(10.9 ; 19.9)$ & $34.8(28.9 ; 41.3)$ \\
\hline Q5 - richest & $11.7(8.5 ; 15.8)$ & $36.1(30.6 ; 41.9)$ & $14.0(10.3 ; 18.8)$ & $34.3(28.6 ; 40.4)$ \\
\hline \multicolumn{5}{|l|}{ Night } \\
\hline Q1 - poorest & $29.8(24.1 ; 36.2)$ & $52.3(45.3 ; 59.3)$ & $47.2(41.8 ; 52.7)$ & $59.4(53.8 ; 64.8)$ \\
\hline Q2 & $35.2(29.3 ; 41.5)$ & $56.7(50.0 ; 63.2)$ & $46.9(41.3 ; 52.7)$ & $64.8(58.9 ; 70.3)$ \\
\hline Q3 & $36.5(31.0 ; 42.4)$ & $53.1(47.0 ; 59.2)$ & $49.8(44.1 ; 55.6)$ & $74.0(68.4 ; 78.9)$ \\
\hline Q4 & $36.0(30.6 ; 41.6)$ & $54.6(48.6 ; 60.5)$ & $55.8(49.6 ; 61.9)$ & $67.4(61.0 ; 73.2)$ \\
\hline Q5 - richest & $43.7(38.1 ; 49.4)$ & $57.8(51.8 ; 63.5)$ & $56.8(50.7 ; 62.8)$ & $73.4(67.5 ; 78.5)$ \\
\hline
\end{tabular}

